EESTI NSV TEADUSTE AKADEEMIA TOIMETISED 1955, IV kd,, nr. 3 ИЗВЕСТИЯ АКАДЕМИИ НАУК ЭСТОНСКОИ ССР 1955. ТоМ IV, № 3

\title{
О ВЫДЕЛЕНИИ ФЛУОРЕСЦИРУЮЩИХ ВЕЩЕСТВ ИЗ СЛАНЦЕВЫХ СМОЛ
}

\author{
Н. М. Томсон, \\ действительный член Академии наук Әстонской ССР
}

В предыдущем сообщении $\left({ }^{6}\right)$ описан способ выделения флуоресцирующих веществ из сланцевых смол при помощи хроматографического метода М. С. Цвета с использованием летучих растворителей.

При дальнейшем использовании бумажного хроматографического метода выяснилось, что флуоресцирующие вещества с течением времени исчезают с хроматографических полос фильтровальной бумаги, что говорит об их летучести. Из факта летучести следует важный в методическом отношении вывод о возможности количественного определения флуоресцирующих веществ по времени их исчезновения, которое колебалось от суток в случае смол, выделенных из пыли атмосферного воздуха и из выхлопных газов двигателей внутреннего сгорания $\left({ }^{4,7}\right)$, до нескольких месяцев в случае камерных сланцевых смол.

Явление летучести позволяет сделать вывод о возможности проникновения в организм паров летучих веществ через огромную дыхательную поверхность легких (суммарная поверхность легочных альвеол, как известно, составляет в среднем около 90 кв. м) из загрязненного воздуха. Флуоресцирующие вещества состоят из ароматических многоядерных углеводородов, которые хорошо растворяются в жирах и холестериноподобных веществах кожного сала, выделяемого в количестве около 20 г в сутки со всей поверхности кожи, равной в среднем 1,7 кв. м. Следовательно, поверхность кожи может служить путем для проникновения летучих углеводородов в организм при непосредственном соприкосновении кожи со смолами, а также из смоляных пятен на одежде, откуда углеводороды испаряются под влиянием нагревания от температуры тела. С одежды пары углеводородов проникают в пододежные слои, где создаются благоприятные условия для более или менее длительного контакта паров с поверхностью кожи. Углеводороды, растворяясь в кожном сале, проникают во внутреннюю среду организма через кожу по путям передвижения холестерина, входящего в состав каждой клетки организма.

Летучесть флуоресцирующих веществ доказывается не только их исчезновением с течением времени, но и переходом на приложенную к хроматограмме чистую фильтровальную бумагу и хлопчатобумажный материал при непосредственном контакте. Уже через сутки на бумаге или текстиле под люминесцентной лампой виден отчетливый отпечаток, по своим очертаниям соответствующий расположению флуоресцирующих 
веществ на хроматограмме. Флуоресцирующие вещества содержат ароматический многоядерный углеводород - 3,4-бензпирен, обладающий раздражающими и канцерогенными свойствами $(1,2,3,5)$. Поэтому с точки зрения гигиены необходимо сделать выводы о недопустимости контакта сланцевой смолы с кожей, а если это случилось, то нужно немедленно очистить кожу от смолы, не допускать загрязнения одежды сланцевыми смолами; запачканную сланцевой смолой одежду нужно немедленно сменить и выстирать; не следует также хранить открытую тару со смолами в закрытых помещениях, где находятся люди; при

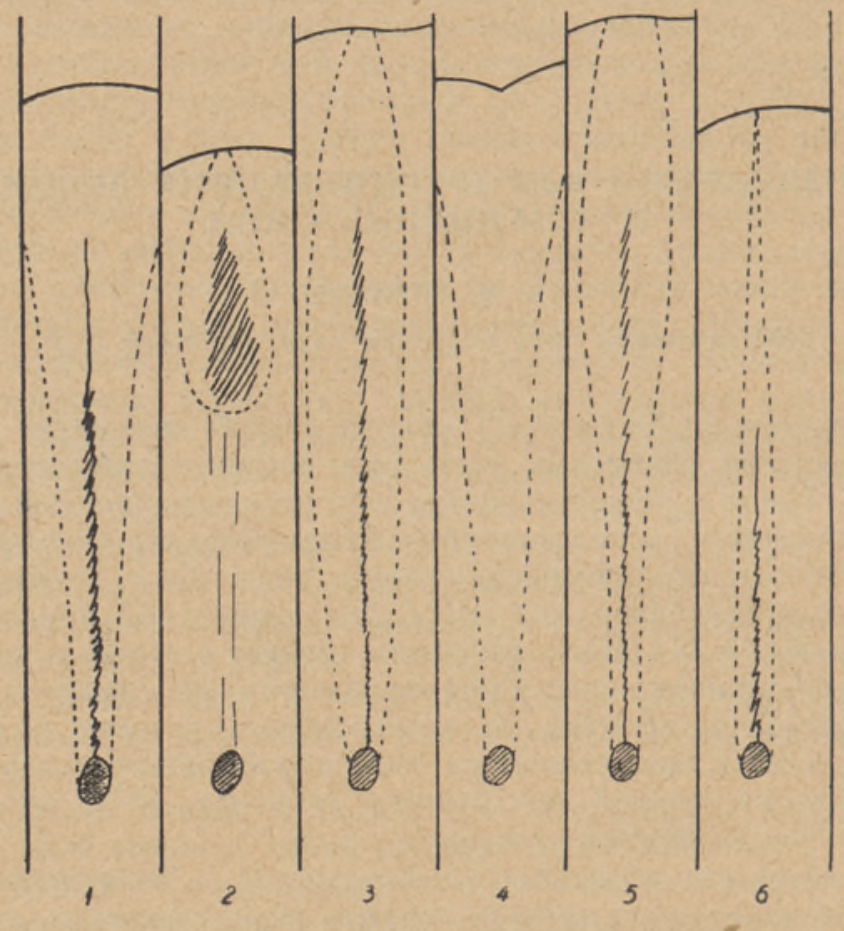

Рис. 1. Хроматограмма смол. В качестве растворителей использованы масла: 1 - вазелиновое, 2 - кедровое, 3 - подсолнечное, 4 - репейное, 5 - оливковое,

$$
6 \text { - касторовое. }
$$

работе со сланцевыми смолами необходимо выполнять все требования личной гигиены - мытье, душ, ванна, ежедневная смена белья и производственной одежды.

Летучие органические растворители при бумажном хроматографическом анализе $\left({ }^{6}\right)$ позволяют хорошо отделить из сланцевой смолы флуоресцирующие вещества, но вследствие улетучивания последних создается препятствие для дальнейшего их изучения. Принимая во внимание способность масел растворять эти вещества, мы использовали их в качестве растворителей при бумажном хроматографическом анализе из-за способности связывать и выделять флуоресцирующие вещества и препятствовать их улетучиванию.

Бумажный хроматографический анализ с применением в качестве растворителей масел производился на полоске фильтровальной бумаги длиной 300 мм, шириной 30 мм, на нижний конец которой наносилась капелька сланцевой смолы величиной от 5 до 1 мм. При пятне размером до 1 мм флуоресцирующие вещества могут быть выделены полностью, 
тогда как при большем размере пятна даже в течение недели не удается полностью отделить их от других темноокрашенных веществ.

Испытанные в качестве растворителей при хроматографическом анализе масла можно разделить на три группы в соответствии с распределением флуоресцирующих веществ на хроматограмме (рис. 1).

Вазелиновое (нефлуоресцирующее) и репейное масла показали сходную картину распределения флуоресцирующих веществ, при которой последние поднимаются вверх в виде расширяющейся полосы. Посередине флуоресцирующей полоски поднимается небольшое количество веществ желтого цвета, которые скопляются в верхней части хроматограммы. В репейном масле количество желтых веществ значительно меньше и едва заметно.

Подсолнечное, оливковое, абрикосовое, камфарное, касторовое масла, рыбий жир и глицерин дают равномерной ширины или суживаюшуюся кверху полоску. Посередине поднимается более заметная темная полоска, которая не достигает верхнего фронта.

В случае применения кедрового масла получается иная картина. Поднимается значительно болышее количество окрашенных веществ в виде каплеобразной фигуры острым концом вверх, окруженной флуоресцирующими веществами, которые полностью отрываются от первоначального пятна.

При летучих органических растворителях хроматограмма высотой 70 мм получается в течение одного часа, при употреблении в качестве растворителей масел для получения того же размера хроматограммы требуется 24 часа. В последующие сутки скорость поднятия постепенно уменьшается и на седьмые сутки составляет не более 10 мм. Различные масла показали различную скорость поднятия за первые сутки - от 15 до 90 мм. Интенсивность флуоресценции при использовании в качестве растворителей масел более значительна, чем при летучих органических растворах, и с течением времени не ослабляется в заметной степени. Цвет флуоресщирующих веществ менялся от светлоголубого до синего и фиолетового оттенка, что зависит, вероятно, не только от коншентрации, но и от наличия различных химических соединений. В хроматограммах сланцевых смол при размере пятна меньше 1 мм флуоресцирующие вещества полностью вымываются из первоначального пятна в течение суток при применении в качестве растворителей подсолнечного и оливкового масла, а при вазелиновом и репейном маслах полного вымывания не наблюдается даже через неделю. При оливковом масле после полного вымывания голубых флуоресцирующих веществ наблюдается поднятие веществ с желтой флуоресценцией.

Интенсивность флуоресценции бывает достаточной для получения спектра с хроматограммы в отраженных ультрафиолетовых лучах при помоши стеклянного монохроматора. Однако при извлечении флуоресцирующих веществ из бумажной хроматограммы в раствор линии спектра получаются более интенсивными.

Для спектрального анализа выделение. флуоресцирующих веществ из смол можно произвести путем фильтрации через хроматографическую колонку, состоящую из стеклянной трубки длиной 400 мм и диаметром 8 мм, заполненную кремнеземом. 50 мг смолы, растворенной в 1 мл бензола, вносится в колонку (бензол необходим для предотвращения возможности прилипания смолы к стеклу). Сверху колонка заливается вазелиновым маслом. Через сутқи в,азелиновое масло проходит через всю длину колонки и приобретает интенсивную желтую окраску. Через вторые сутки фильтруется вазелиновое масло уже слабо желтого цвета, а на третьи сутки - совершенно прозрачное вазелиновое масло, имеющее яркую флуоресценцию. Таким образом удается отделить флуоресцирующие 
вещества от других темноокрашенных веществ. Последние проникают в кремнезем на глубину не более 50 мм.

Распределение составных частей смолы зависит от физико-химических свойств смолы, растворителя, пористой среды и от их взаимодействия. Подвижность составных частей смолы зависит также от величины молекулы. Поэтому легкие молекулы поднимаются в первую очередь и располагаются у переднего фронта растворителя. Синие и голубые флуоресцируюшие вешества поднимаются одновременно, но синие вещества, как более легкие, идут впереди, а после них поднимаются флуоресцирующие фиолетовым и желтым цветом вещества. Дальнейшее изучение флуоресцирующих веществ проводится посредством флуоресцентного и абсорбционного спектральных анализов.

Масла в качестве растворителей при хроматографическом анализе имеют преимущества перед летучими органическими растворителями, так как они связывают флуоресцирующие вещества и сохраняют их в течение длительного времени без ослабления при незначительном поднятии темноокрашенных веществ.

Поступила в редакцию $3 \mathrm{~V} 1955$

\section{ЛИТЕРАТУРА}

1. Б. П. Г уринов, Ф. Д. Машбиц и Л. М. Ша бад, Исследование бластомогенного действия некоторых смол, полученных из атмосферной пыли и прп сжигании различных видов топлива, жГигиена и санитария», № 10,1954 .

2. Н. M. Томсон, Загрязнение атмосферного воздуха продуктами неполного сгопания топлива и их гигиеническое значение, «Гигиена и санитария», № 2 , 1950.

3. Н. М. Том сон, К вопросу о профилактике рака, «Гигиена и санитария», № 11 , 1951.

4. Н. М. Том сон, Методика флуоресцентного спектрального анализа некоторых ароматических углеводородов, Известия АН ЭССР, т. I, № 3, 1952.

5. Н. М. Томсон, Об определении смолистых веществ в задымленном воздухе, Известия АН ЭССР, т. II, № 2, 1953.

6. Н. М. То м сон, Хроматографический анализ сланцевых масел, Известия АН ЭССР, T. III, № $1,1954$.

7. P. Kotin, H. L. Falk and M. Thom as, Aromatic Hydrocarbons, III. Presence in the Particulate Phase of Diesel-Engine Exhausts and the Cancerogenicity of Exhaust Extracts. A. M. A. Archives of Industrial Health, Vol. 11, No 2, 1955. 